but I did not feel that Torrance always adequately observed the distinction.

As a matter of historical fact the Christian doctrine of creation helped men to recognize (i) and (ii) and so made possible the scientific revolution. By a curious twist, the Newtonian mechanical world view then tended to abolish the recognition of (iii) and (iv).

The presence of contingence in the world is combined with a high degree of intelligibility which enables us to understand it. Torrance says "The intelligibility of the universe provides science with its confidence but the contingence of the universe provides science with its challenge"' (p.58). Such a view of the world is certainly consistent with the doctrine that it is the work of the sovereign will of the Creator and that its rationality is the reflection of his mind. Torrance seems to argue that only such a doctrine is possible but I cannot agree that there is that degree of intellectual compulsion. He sees creation as implying two complementary aspects. First, the world is wholly dependent on God since without his sustaining it would collapse back into nothingness. From this comes its contingent order. Second, the world is other than God (no pantheism!) so that he has made it to stand apart from him. The first aspect is the concern of theology; the second that of science whose method is to proceed etsideus non daretur, as if God did not exist. A true understanding requires a synthesis of these aspects.

A test of any world view is its understanding of evil. Torrance equates evil with disorder but nevertheless (rightly I believe) does not go along with Augustine and Aquinas in seeing it as just the absence of good. I thought his discussion needed a more thorough-going eschatological dimension. Also, I did not always recognize the world of science as Torrance described it. He attributes a release from the shackles of Newtonian necessity to the creation of the field concept and to the genius of Einstein. I cannot see that. Partial differential equations have propagation properties as rigorous as those of ordinary differential equations and causality finds its place within the lightcone of relativistic physics. Further, I did not understand his attitude to mathematics. $\mathrm{He}$ does not like to accord it true intellectual independence (that would be dangerously Platonic and Plato's ideas are possible rivals to God in his eyes) so he says it has a "natural bond with nature". Again, I do not see that.

The book is written in a style which might be described as "Scottish professorial", a sort of intellectual cousin to the elaborate castellation of Scottish baronial. Certainly, it does not make for easy reading or rapid assimilation.

John Polkinghorne, formerly Professor of Mathematical Physics at Cambridge, is a Fellow of Trinity College and an Anglican clergyman.
How not to make a splash in science

\section{Robert Ubell}

Polywater. By Felix Franks. Pp.208. ISBN 0-262-06073-6. (MIT Press: 1981.) \$15, $£ 9.30$.

In the early $1960 \mathrm{~s}$ in an obscure laboratory in Kostroma, 190 miles from Moscow on the upper Volga, an equally obscure research scientist, Nikolai Fedyakin, stumbled on a surprising phenomenon. Looking at how liquids behave in very narrow capillaries, he watched as a dense new liquid formed in neighbouring empty tubes.

In Moscow, the renowned physical chemist B.V. Deryagin quickly recognized the possible implications of Fedyakin's "discovery" and took it for his own. He set an entire laboratory to work on it, published results widely and campaigned for the recognition of anomalous water at Faraday Society and Gordon Research conferences. The new liquid was 15 times denser than normal water, boiled at temperatures much higher than $100^{\circ} \mathrm{C}$ and froze, without forming ordinary ice, at under $-30^{\circ} \mathrm{C}$. For a time, Western scientists either yawned or sneered. Some guessed it wasn't water at all, but the result of contamination. Yet excitement grew, and in England attempts were made to replicate the Russian work. J.D. Bernal, in private, called Deryagin's achievement "the most important physical-chemical discovery of this century".

The US Office of Naval Research jumped in next, sensing that the mysterious new form of water might have military uses. Ripples of interest swelled to waves: the liquid was given a name - polywater and busy scientists suddenly found the time and money to work on what they had seen as a mere curiosity the previous week. Respected researchers and the overzealous though, at most, only a few drops of polywater had ever been collected.

In 1973 the bubble burst. In a brief, dignified note in Nature, Deryagin reported that he and his colleagues had finally found it impossible to grow polywater from ordinary water. The unique qualities claimed earlier "should be attributed to impurities rather than to the existence of polymeric water molecules"'. The emperor was not well dressed.

Felix Franks escaped the perils of the polywater controversy, but as a distinguished surface chemist and an authority on water he was close enough to record it all. The result is this book. To his great credit, Franks treats those who believed and those who didn't with an even hand, praising little, blaming less. This is a skilfully made book, wise, urbane, alike scrambled to make their mark, even

\section{Nature of "Anomalous Water"}

MANY experiments have corroborated the phenomenon involving the formation of condensates with anomalous properties from the vapours of water and other liquids on silicate surfaces. But the nature of this phenomenon remained obscure for a long time and widely differing hypotheses were put forward to clarify it, one of them involving the formation of stable associates of water molecules $\left(\mathrm{H}_{8} \mathrm{O}\right)_{\mathrm{n}}$. This hypothesis was first formulated by us $^{1-4}$ and was developed further by Lippincott et al. ${ }^{\mathrm{s} \cdot \mathrm{e}}$.

We have established that there are no condensates both free of impurity atoms and simultaneously exhibiting anomalous properties. Consequently, these properties should be attributed to impurities rather than to the existence of polymeric water molecules.

Consequently, the anomalous properties of condensates may be explained, not by the formation of a new modification $o$ water, as was previously supposed, but by the peculiar features of a reaction taking place between the vapour and solid surfaces in the process of condensation. Many aspects of the mechanism of formation of anomalous condensates have not yet been fully clarified. This especially applies to the formation of anomalous condensate on $\mathrm{MgO}$ surfaces ${ }^{19,20}$. Only the general features of the phenomenon are clear as yet; thorough investigation by those studying processes involving the interaction of vapours and solid surfaces is clearly required.

\section{The Institute of Physical Chemistry, $\quad$ B. V. DerJaguin USSR Academy of Sciences N. V. CHURAEV}

The end of polywater. Extracts from the paper by Deryagin (Derjaguin) and Churaev, published in Nature on August 17, 1973. 